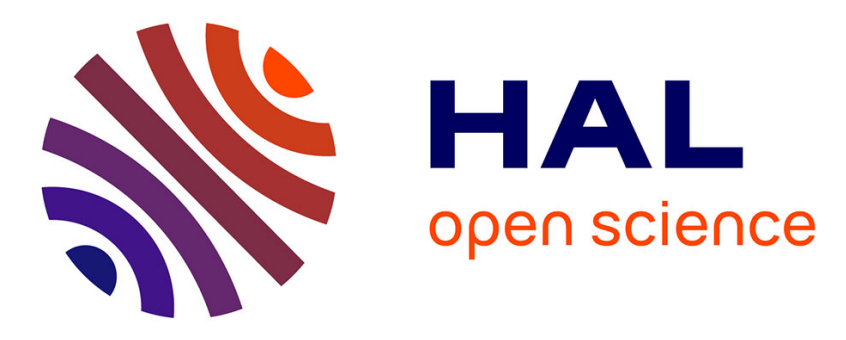

\title{
Quality of life in the management of small vestibular schwannomas: Observation, radiotherapy and microsurgery
}

Sarah Deberge, Anaïs Meyer, Estelle Le Pabic, Lucie Peigne, Xavier Morandi, Benoit Godey

\section{To cite this version:}

Sarah Deberge, Anaïs Meyer, Estelle Le Pabic, Lucie Peigne, Xavier Morandi, et al.. Quality of life in the management of small vestibular schwannomas: Observation, radiotherapy and microsurgery. Clinical Otolaryngology, 2018, 43 (6), pp.1478-1486. 10.1111/coa.13203 . hal-01952365

\section{HAL Id: hal-01952365 \\ https://hal-univ-rennes1.archives-ouvertes.fr/hal-01952365}

Submitted on 12 Dec 2018

HAL is a multi-disciplinary open access archive for the deposit and dissemination of scientific research documents, whether they are published or not. The documents may come from teaching and research institutions in France or abroad, or from public or private research centers.
L'archive ouverte pluridisciplinaire HAL, est destinée au dépôt et à la diffusion de documents scientifiques de niveau recherche, publiés ou non, émanant des établissements d'enseignement et de recherche français ou étrangers, des laboratoires publics ou privés. 
DR SARAH DEBERGÉ (Orcid ID : 0000-0001-5913-5688)

Article type : Original Manuscript

\section{Title:}

Quality of life in the management of small vestibular schwannomas: observation, radiotherapy and microsurgery

\section{Running title:}

Quality of life in management of small vestibular schwannomas

\section{Authors:}

Sarah Deberge ${ }^{1}$, Anais Meyer ${ }^{1}$, Estelle Le Pabic ${ }^{3}$, Lucie Peigne ${ }^{1}$, Xavier Morandi $^{2}$, Benoit Godey ${ }^{1}$

\section{Affiliations:}

${ }^{1}$ Service ORL, CHU de Rennes, faculté de Médecine de Rennes, Université de Rennes 1

${ }^{2}$ Service de Neurochirurgie, CHU de Rennes, faculté de Médecine de Rennes, Université de Rennes 1

${ }^{3}$ Service de Pharmacologie Clinique et Biologique, $\mathrm{CHU}$ de Rennes, faculté de Médecine de Rennes, Université de Rennes 1

\section{Corresponding Author:}

Benoit Godey

Service ORL- CHU de Rennes,

2 rue Henri le Guilloux

35033 Rennes Cedex 09 
France

benoit.godey@chu-rennes.fr

Téléphone: +33299284321

Fax: +33299284194

\section{Acknowledgments:}

The authors would like to thank Ray Cooke for the English translation

\section{Conflict of interests:}

The authors declare that there is no conflict of interests regarding the publication of this paper.

\section{Abstract:}

Objective: The aim of this study was to compare quality of life (QOL) in small unilateral vestibular schwannoma (VS) patients managed by microsurgery, radiotherapy or observation.

Study design: retrospective chart review.

Methods: The study included a total of 142 patients with VS stage 1 or 2 according to the Koos classification and treated between January 2004 and December 2015. Microsurgery, radiotherapy and observation groups comprised 43, 46 and 53 patients, respectively. All patients completed four QOL (questionnaires: Short-Form Health Survey 36, Hearing Handicap Inventory, Tinnitus Handicap Inventory, and Dizziness Handicap Inventory Short-Form. Clinical symptoms and QOL were compared among groups.

Results: The average time interval between management and filling in the questionnaires was 66 months. There was no difference in QOL between the three groups on any of the four questionnaires. The most debilitating symptom was vertigo for all three groups. Tinnitus was a pejorative factor in the surgery group. Hearing level was deteriorated after microsurgery but there was no significant difference between the radiotherapy group and the middle fossa approach.

Conclusion: Patients with small VS stage 1 and 2 had similar QOL, irrespective of management by observation, radiotherapy or microsurgery. The overall predictor for long-term reduced QOL was vertigo. Vestibular rehabilitation could improve QOL in symptomatic patients. 
Keywords: vestibular schwannoma, acoustic neurinoma, quality of life, microsurgery, radiosurgery.

\section{Introduction:}

Vestibular schwannoma (VS) is a benign tumour arising from the Schwann cell sheath of the vestibular part of the eighth cranial nerve.

The most common diagnostic symptoms are cochleovestibular symptoms such as unilateral hearing loss, tinnitus and vertigo. Other clinical symptoms such as facial hypoesthesia, facial nerve paralysis and intracranial hypertension appear only with larger tumors.

Since the 70th, diagnosis of small VS was already a routine procedure with invasive neuroradiological procedures. With widespread access and improved magnetic resonance imaging (MRI) techniques, VS can nowadays be detected incidentally and earlier with an increasing number of patients presenting with small tumours and few symptoms (1). The incidence of diagnosed VS increased from 3.1 per million per year in 1976 to 19 per million per year in 2008 (1). Moreover, the natural history of VS growth is now well known (2) and the majority of tumours are slow-growing $(3,4)$.

The best management remains controversial for small and medium-sized VS tumours. Treatments include observation, radiotherapy (RT) and microsurgery (MS) via a hearing preservation (retrosigmoid or middle fossa approach) or translabyrinthine approach. The choice of treatment depends on several criteria such as patient age, comorbidity, tumour size and location, hearing status and patient preference.

In recent decades, quality of life ( $Q O L)$ has become an important issue for patients and clinicians to decide the best treatment option. The aim of this study was to analyze data from four questionnaires, the Short-Form Health Survey (SF-36), the Hearing Handicap Inventory ( $\mathrm{HHI})$, the Tinnitus Handicap Inventory (THI) and the Dizziness Handicap Inventory Short-Form (DHI short-form), that assess QOL to compare the outcomes of MS, RT and observation for VS stages 1 and 2 according to the Koos classification (5). We though to establish factors predictive of worse QOL in each group. 


\section{Ethical considerations}

The university hospital ethics committee approved the study.

\section{Material and methods}

\section{Design:}

This retrospective monocentric study included all patients from January 2004 to December 2015 presenting unilateral VS stage 1 or 2 according to the Koos classification in a tertiary care centre.

\section{Criteria of selection:}

168 patients with VS stage 1 (VS in the internal auditory meatus) or 2 (VS in the internal auditory meatus and cerebellar pontine angle without any touch the brainstem) of Koos classification were managed in our centre including 64 patients who underwent observation, 53 who received RT and 51 who underwent MS. Exclusion criteria were neurofibromatosis type 2, tumour stages 3 or 4 and age younger than 18 years. Patients were divided into three treatment groups: observation group, RT group with Gammaknife $\AA^{\circ}$ or Cyberknife $\AA$, and MS group with translabyrinthine or middle fossa approach.

\section{Data:}

Size of tumour was measured by MRI in axial constructive interference in steady state (CISS) T2. Preand post therapeutic data were collected: hearing level graded by the Gardner-Robertson scale (6); Hearing threshold deterioration between initial diagnosis and just before treatment for radiotherapy and microsurgery and between diagnosis and last news for the observation group; facial function using the House-Brackmann scale (7); clinical symptoms such as tinnitus and vertigo, post-surgical or radiation complications and recurrent tumours. Hearing preservation was correlated to invasion of internal auditory meatus fundus; invasion of the cochlear fossa; intensity of cochlear fluid T2 as compare to contralateral one. 


\section{Questionnaires:}

QOL was assessed by using four questionnaires. All patients completed four questionnaires (SF-36, $\mathrm{HHI}, \mathrm{THI}, \mathrm{DHI}$ short-form). The SF-36 is a validated questionnaire used to assess the general QOL of patients following surgical or medical therapies. It consists of 36 items and assesses 8 different health conditions including physical functioning, role limitations due to physical or emotional problems, body pain, general health, vitality, social functioning, and mental health (8). It also provides a physical component summary score and a mental component summary score. Scores range from 0 to 100 , higher scores meaning better QOL. The HHI questionnaire assesses five social questions and five emotional questions and gives a total score, an emotional score and a social score (9). The answer "yes" gives 4 points, "sometimes" 2 points and "no" zero points. A overall score over eight points exhibits a lack in QOL related with hearing loss. The THI is a 25 -item questionnaire that classifies tinnitus intensity in five categories: from mild to catastrophic (10). The DHI short-form evaluates the functional, emotional and physical effects of dizziness and contains 13 questions: 5 on physical function, 2 on emotional function and 6 on functional issues (11).

\section{Statistical analyses}

Quantitative variables were described as mean +/- standard deviation. Comparisons of baseline demographics, clinical outcomes and HRQOL outcomes in the three groups were evaluated using the Kruskal-Wallis test for continuous and ordinal features, while the chi-square and Fisher exact tests were used to analyze categorical variables. The Student t-test or the non-parametric tests of MannWhitney Wilcoxon were used to compare the groups. To compare before and after treatment in each group regarding hearing level, vertigo and tinnitus, the Wilcoxon test was used for quantitative variables and the McNemar test for qualitative variables. Multivariable analyses were performed using ANCOVA. $p$ values less than 0.05 were considered statistically significant.

\section{Results}

Fifty-three observation patients (82,8\%), 46 radiated patients $(86,8 \%)$ (including 7 with Cyberknife ${ }^{\circledR}$ radiation: three sessions of 6.5 Gy and 39 with Gammaknife $\AA$ radiation: 12 Gy in one session) and 43 patients $(84.3 \%)$ undergoing MS gave their consent to participate in the study and returned completed questionnaires. 
Patients with small no growing tumour were observed. Young patients with growing tumour stage 2 were operated by middle fossa approach if hearing was preserved or translabyrinthine approach if hearing was deteriorated. Older patients were treated by RT for growing tumour or MS if they were in good health and if tumour was near the brainstem.

Surgical approaches were as follows: 15 patients though middle fossa approach and 28 patients though translabyrinthine approach. The choice of approach depended on the serviceable hearing. In the translabyrinthine approach group, 6 patients had a class A or B hearing class. 3 were aged from 69 to 73 years old and translabyrinthine approach was chosen to avoid a cerebellar or temporal lobe retraction. 3 patients had an invasion of the cochlear fossa with alteration of auditory evoked potential, they were considered with no chance of hearing preservation. No retrosigmoid technique was performed. Patients' characteristics and clinical data before treatment are described in Table 1 and after treatment in Table 2. Patients in the observation group were older than the remnant of the cohort and their tumours were smaller than those in the other groups $(p<0.001)$. Groups were similar concerning number of patients, gender, initial hearing, initial facial function, vertigo and tinnitus. The average interval between management and filling in the questionnaires was 66 months. The follow-up period was significantly longer in the MS group (81 months) than in the RT group (57 months) ( $p=$ 0.006). Hearing level in the MS group was significantly lower than in the other groups. There was no significant difference in hearing level between the RT group and the middle fossa approach group $(p=0.46$ ). Facial palsy rate in the MS group was $13.9 \%$ (House-Brackmann grade 3 to 5 ), $20 \%$ and $10 \%$ for middle fossa and translabyrinthine approach respectively. There was no correlation between hearing threshold degradation, staging, size and tumour growth in observation and RT group. Staging of tumour was correlated to hearing loss in the MS group ( $p=0.0094)$. Hearing threshold degradation before treatment was higher in MS group $(p<0.001)$.

In the observation group, 6 patients (11.3\%) had growing tumour and $47(88.7)$ had stable tumors. The mean growth was $1.27 \pm 0.69$ per year. There was no correlation between hearing loss and VS growth $(p=0.1790)$.

Radiological features were studied as a function of hearing loss after treatment. No correlation was observed between hearing loss after treatment and Invasion of internal auditory meatus fundus $(p=$ 0.4182 for RT group; $p=0.1282$ for MS group), invasion of the cochlear fossa ( $p=0.1996$ for RT group; $p=0.0633$ for MS group), intensity of cochlear fluid T2 signal as compare to contralateral one ( $p=0.7133$ for RT group; $p=0.4058$ for MS group).

The table 3 compares results between middle fossa approach and translabyrinthine approach. Mean time of follow up, tumour size, stage of tumour, tinnitus and vertigo were the same between two groups. Hearing level and facial nerve function were higher in patients undergoing the middle fossa approach as compared to the translabyrinthine approach. Surgical complications were hematoma (1 
case) that needed another surgical step, cerebrospinal fluid leakage resolved with cerebrospinal fluid diversion by lumbar drain ( 1 case), and wound infection ( 1 case) treated with local therapy. One patient presented a residual tumour treated secondarily by radiation.

In the RT group, 4 patients (8.7\%) underwent a surgical resection. One patient was operated 1 year after RT for a tumour that grew from 12 to $22 \mathrm{~mm}$. Two patients were operated 2 years after RT for a tumour growth of from 10 to $15 \mathrm{~mm}$ and from 9 to $16 \mathrm{~mm}$. One patient was operated 3 years after RT for a tumour growth from 17 to $28 \mathrm{~mm}$. Tumour growth rate was the same before and after treatment and all of these patients were treated by gammaknife. There was no difference of SF-36 scores between these four patients and the other patients of the RT group. There was no difference between tumour control $(p=1.00)$ and hearing preservation $(p=0.17)$ between treatment by gammaknife and treatment by cyberknife.

SF-36 results are shown in Table 4. There were no differences between the three groups for physical $(p=0.67)$ or mental health measures $(p=0.59)$. No difference for physical or mental health measures were found between middle fossa or translabyrinthine approach. Table 5 shows the physical and mental scores for all patients and for each group in relation to vertigo or tinnitus. Tinnitus impacted mental scores and vertigo impacted both physical and mental scores in all patients $(p<0.05)$. Vertigo affected physical and mental scores of patients in both the observation and MS groups but affected only the mental score in the RT group. Tinnitus affected both the physical and mental scores in the MS group. Mean hearing threshold had no consequence on physical or mental scores in any group (Mann-Whitney Wilcoxon $0.06<\mathrm{p}<0.90$ ). Facial function did not affect physical or mental scores in any group (Mann-Whitney Wilcoxon physical score $p=0.36$, mental score $p=0.65$ )

There was no significant difference between the groups for total $\mathrm{HHI}$, emotional $\mathrm{HHI}$, social $\mathrm{HHI}$ or auditory disorders (Table 6). Furthermore, there was no significant difference between the groups for any THI scores (Table 7). There were no significant differences across management options between scores on the global DHI test and on the emotional, functional and physical DHI tests (Table 8). In the MS group, there were no significant differences in the results obtained from the four questionnaires between the two approaches (Mann-Whitney Wilcoxon $0.40<p<0.96$ ). A multivariant analysis suggested that time to management had no impact on the results obtained on any of the questionnaires and in any of the patients in the study (ANCOVA $0.26<p<0.99$ ). 


\section{Discussion}

There were no significant differences in QOL using the SF-36 questionnaires between the three groups. While numerous studies have evaluated VS outcomes, the best management of patients with small VS is still controversial and issues relating to QOL are of paramount importance. To our knowledge, this is the first retrospective study to use a global QOL questionnaire and specific questionnaires to quantify impaired QOL due to hearing loss, dizziness and tinnitus in observation, RT and MS groups.

In a prospective study with these three groups, Di Maio et al (12) did not find any difference in QOL. Robinett et al. (13) found that between 1 to 5 years post-management, the RT group had higher QOL scores than the MS group, while there was no difference after 5 years. Pollock et al. (14) showed that within three months after surgery, patients had a statistically significant decline in several of the SF-36 domains like physical functioning, role physical, energy and overall physical. After three months of follow-up, there was no difference between the RT and MS groups. The mean follow-up for our three groups was 66 months (61, 57 and 81 months for the observation, RT and MS groups, respectively) (Table 2), so this cannot explain why we did not find any difference. Our patients in the observation group had smaller tumours, as also reported by Di Maio and al (12). They were older than the remnant of the cohort and the MS group was younger than the other two groups, as in the studies by Carlson et al. (15) and Pollock et al (14).

Gauden et al. (16) showed that the SF-36 was the most common questionnaire used to study QOL in SV. Different studies have compared the three groups and found different results. Carlson et al. (15) and Myrseth et al. (17) found no difference between the three groups. Kim et al. (18) found that QOL was greater after MS than after RT. Three studies showed that MS patients had worse QOL than those in the other groups $(19,14,20)$. Soulier et al. (21) reported better QOL in patients with small tumours $(<10 \mathrm{~mm})$ undergoing observation because there was no active treatment, so patients did not feel sick. Betchen et al. (22) showed that post-operative hearing, facial functioning and time since MS had no significant impact on QOL as assessed by the SF-36. Da Cruz et al. (23) found no difference between MS approach, tumour size, sex and age

Patients undergoing observation may have a greater psychological burden because of the knowledge that the tumour is still present and could potentially grow. Regular imaging may remind them their pathology and increase their anxiety of developing new symptoms. On the other hand, they may not feel that their disease is aggressive because their doctors did not recommend any active treatment. 
For patients who receive RT, treatment efficacy can be assessed only after several years by MRI and not after the first MRI check-up. Moreover, patients may be worried by the transient increase in size in their tumour due to oedema that can occur in the months following RT. Four patients needed surgery after radiotherapy and it was not associated to a decrease of QOL. Those undergoing MS may experience less anxiety after a complete resection with a feeling of being definitively cured, despite side-effects such as hearing loss and facial palsy.

In our study, hearing loss did not influence QOL in the three groups. Hearing deterioration between the diagnosis and management was equivalent in observation and RT group and was higher in MS group despite a similar follow up. A more aggressive tumour on the cochlear nerve in the MS group could explain this difference. Lloyd et al. (24) did not find any correlation between hearing level and quality of life with conservative management, whereas Brooker et al. (25) showed that hearing loss was very likely to have a severe psychological impact on QOL. Hearing loss was not responsible for overall reduced hearing loss-related QOL because speech understanding and stereophony were already affected before management in many patients. A decrease in hearing level due to the treatment had only little effect on binaurality and QOL.

Kim et al (26) found that the increased cochlear signal of intracanalicular VS on 3D FLAIR images was correlated with the degree of hearing impairment, and that the degree of correlation was stronger with tumours confined to the internal auditory meatus compared with the result of all patients, though there was no correlation with tumours extending to the cerebellopontine cistern. As Lee et al. (27), we found no correlation between the audiometric results and the degree of the signal increase of the cochlea or invasion of the cochlear fossa or invasion of the internal auditory meatus fundus.

There was no difference in SF-36 results in patients with or without facial palsy. Facial palsy obviously affects QOL so this finding was probably due to a lack of pertinence of the questionnaires regarding this symptom. Kelleher et al. (28) found the same conclusion with the SF-36.

In our study, tinnitus was a prognostic factor of impaired QOL only in the MS group, whereas Lloyd et al. (24) and Kim JH et al. (18) found it to be a significant symptom in the observation group. Vertigo was a predictive symptom of reduced $\mathrm{QOL}$ in the three groups, as already reported elsewhere. Four studies $(24,25,28,29)$ showed that dizziness was the most significant audio-vestibular predictor of QOL when management was conservative (observation or RT) Patients who were observed or who had RT had residual ipsilateral symptoms owing to unilateral vestibular hypofunction and most subjects in the MS group reported central compensation with a significant improvement in symptoms after a period of several weeks or months. Vestibular rehabilitation could improve balance disorder by allowing central compensation. 
Since the study was retrospective, the delay between management and evaluation was different between patients with a longer delay in the MS group and those in the RT group. However, multivariate analysis did not find that the difference in delay influenced the responses on the questionnaires. Differences in delay between the groups may be explained by the therapeutic attitude in our centre, which was more surgical in the early 2000 s and has since become more conservative. Small tumours are operated via a translabyrinthine approach when the preoperative hearing level is not sufficient for understanding speech and via the middle fossa approach to preserve hearing.

In our study, 7 patients were treated by Cyber knife in three sessions of 6.5 Gy versus 39 by Gamma knife in a single session of 12Gy and there was no difference between tumour control and hearing between these two treatments. A study of Combs et al. (30) found that local control of VS was $97 \%$ at 36 months, $95 \%$ at 60 months, and $94 \%$ at 120 months with no difference between fractionated dose or single dose of RT ( $p=0.39$ ). After $R T$, hearing preservation was observed in $85 \%$ of the patients. Loss of hearing was the same in both groups.

In our study, patients in the control group were older than the other groups. Tumour growth was less important in a subject who has a limited life expectancy. There is no treatment indication for VS stage 1 and no acceptable treatment for VS stage 2 in the elderly (31). Tumour growth and Koos stage in the observation group were smaller than the other groups. Even though there is no risk of brainstem compression in a short-term time frame, this is an argument which prescribes for observation in the VS stage 1 group. The risk of facial nerve palsy was $13,9 \%$ in the MS group, $20 \%$ and $10 \%$ for middle fossa and translabyrinthine approach respectively. This is, again, another argument for a nonintervention in small tumours, even if there is no difference between the QOL questionnaires among the MS and the other groups.

Hearing deterioration was limited in the control group, more advanced in the RT group and higher in the MS group. These data suggest that patients with functional hearing have to be observed.

Treatment should be proposed if the tumour growths and becomes dangerous for the brainstem. In general, comparable quality of life following the three treatment options does not mean that all three options are justified. The facial nerve weakness and the loss of hearing are factors that need to be seriously considered. The choice of the management depends also of the life experience, the general status and the personal choice of the patient.

\section{Conclusion:}

This study shows that patients with small VS report similar QOL whatever the management strategy used, as in many previous studies. These three treatments are acceptable for small VS but the high score of facial nerve palsy in the MS group suggest that surgery must be done if no other management is possible. No deterioration in QOL scores in patients with facial palsy was probably 
due to a lack of pertinence of the questionnaires regarding this symptom. MS is not recommended neither for the VS stage 1 nor for elderly patients who are not in a good state of health. Hearing preservation is possible in the observation group and in the RT group, even if hearing preservation was less good in RT group. Patients with functional hearing must be closely observed. Given the success rates of RT and watchful- waiting, MS for small VS should be not recommended.

Vertigo is the principal cause of QOL deterioration in the management of VS.

\section{References:}

1. Stangerup S-E, Tos $M$, Thomsen J, Caye-Thomasen $P$. True incidence of vestibular schwannoma? Neurosurgery 2010;67:1335-1340.

2. Stangerup S-E, Caye-Thomasen P. Epidemiology and Natural History of Vestibular Schwannomas. Otolaryngol Clin North Am 2012;45:257-268.

3. Varughese JK, Breivik CN, Wentzel-Larsen T, Lund-Johansen M. Growth of untreated vestibular schwannoma: a prospective study. J Neurosurg 2012;116:706-712.

4. Martin TPC, Senthil L, Chavda SV, Walsh R, Irving RM. A protocol for the conservative management of vestibular schwannomas. Otol Neurotol 2009;30:381-385.

5. Koos WT. Criteria for preservation of vestibulocochlear nerve function during microsurgical removal of acoustic neurinomas. Acta Neurochir (Wien) 1988;92:55-66.

6. Gardner G, Robertson JH. Hearing Preservation in Unilateral Acoustic Neuroma Surgery. Ann Otol Rhinol Laryngol 1988;97:55-66.

7. House JW, Brackmann DE. Facial nerve grading system. Otolaryngol--Head Neck Surg 1985;93:146-147.

8. Ware JE, Gandek B. Overview of the SF-36 Health Survey and the International Quality of Life Assessment (IQOLA) Project. J Clin Epidemiol 1998;51:903-912.

9. Ventry IM, Weinstein BE. Identification of elderly people with hearing problems. ASHA 1983;25:37-42.

10. Ghulyan-Bédikian V, Paolino M, Giorgetti-D’Esclercs F, Paolino F. Psychometric properties of a French adaptation of the Tinnitus Handicap Inventory. Encephale 2010;36:390-396.

11. Tesio L, Alpini D, Cesarani A, Perucca L. Short form of the Dizziness Handicap Inventory: construction and validation through Rasch analysis. Am J Phys Med Rehabil 1999;78:233-241.

12. Di Maio S, Akagami R. Prospective comparison of quality of life before and after observation, radiation, or surgery for vestibular schwannomas. J Neurosurg 2009;111:855-862.

13. Robinett ZN, Walz PC, Miles-Markley B, Moberly AC, Welling DB. Comparison of Long-term Quality-of-Life Outcomes in Vestibular Schwannoma Patients. Otolaryngol-Head Neck Surg 2014;150:1024-1032. 
14. Pollock BE, Driscoll CLW, Foote RL, Link MJ, Gorman DA, Bauch CD, et al. Patient Outcomes after Vestibular Schwannoma Management: A Prospective Comparison of Microsurgical Resection and Stereotactic Radiosurgery: Neurosurgery 2006;59:77-85.

15. Carlson ML, Tveiten OV, Driscoll CL, Goplen FK, Neff BA, Pollock BE, et al. Long-term quality of life in patients with vestibular schwannoma: an international multicenter cross-sectional study comparing microsurgery, stereotactic radiosurgery, observation, and nontumor controls. $\mathrm{J}$ Neurosurg 2015;122:833-842.

16. Gauden A, Weir P, Hawthorne G, Kaye A. Systematic review of quality of life in the management of vestibular schwannoma. J Clin Neurosci 2011;18:1573-1584.

17. Myrseth E, Møller P, Pedersen P-H, Lund-Johansen M. Vestibular schwannoma: surgery or gamma knife radiosurgery? A prospective, nonrandomized study. Neurosurgery 2009;64:654661.

18. Kim HJ, Jin Roh K, Oh HS, Chang WS, Moon IS. Quality of Life in Patients With Vestibular Schwannomas According to Management Strategy: Otol Neurotol 2015;36:1725-1729.

19. Tran Ba Huy P, Kania R, Legac M-S. [Vestibular schwannoma (acoustic neurinoma). Natural history and quality of life]. Bull Acad Natl Med 2008;192:1725-1737.

20. Sandooram D, Grunfeld EA, McKinney C, Gleeson MJ. Quality of life following microsurgery, radiosurgery and conservative management for unilateral vestibular schwannoma. Clin Otolaryngol Allied Sci 2004;29:621-627.

21. Soulier G, van Leeuwen BM, Putter H, Jansen JC, Malessy MJA, van Benthem PPG, et al. Quality of Life in 807 Patients with Vestibular Schwannoma: Comparing Treatment Modalities. Otolaryngol Neck Surg 2017;157:92-98.

22. Betchen SA, Walsh J, Post KD. Self-assessed quality of life after acoustic neuroma surgery. J Neurosurg 2003;99:818-823.

23. Da Cruz MJ, Moffat DA, Hardy DG. Postoperative Quality of Life in Vestibular Schwannoma Patients Measured by the SF36 Health Questionnaire: Postoperative Quality of Life in Vestibular Schwannoma Patients Measured by the SF36 Health Questionnaire. Laryngoscope 2000;110:151-155.

24. Lloyd SKW, Kasbekar AV, Baguley DM, Moffat DA. Audiovestibular factors influencing quality of life in patients with conservatively managed sporadic vestibular schwannoma. Otol Neurotol 2010;31:968-976.

25. Brooker JE, Fletcher JM, Dally MJ, Briggs RJS, Cousins VC, Malham GM, et al. Factors associated with symptom-specific psychological and functional impact among acoustic neuroma patients. J Laryngol Otol 2014;128:S16-26.

26. Kim DY, Lee JH, Goh MJ, Sung YS, Choi YJ, Yoon RG et al. Clinical significance of an increased cochlear 3D fluid-attenuated inversion recovery signal intensity on an MR imaging examination in patients with acoustic neuroma. Am J Neuroradiol. 2014 Sep;35(9):1825-1829.

27. Lee $\mathrm{IH}, \mathrm{Kim}$ HJ, Chung WH, Kim E, Moon JW, Kim ST et al. Signal intensity change of the labyrinth in patients with surgically confirmed or radiologically diagnosed vestibular schwannoma on isotropic 3D fluid-attenuated inversion recovery MR imaging at 3T. Eur Radiol. 2010 Apr;20(4):949-957.

28. Kelleher MO, Fernandes MF, Sim DW, O'Sullivan MG. Health-related quality of life in patients with skull base tumours. Br J Neurosurg 2002;16:16-20. 
29. Breivik CN, Varughese JK, Wentzel-Larsen T, Vassbotn F, Lund-Johansen M. Conservative management of vestibular schwannoma--a prospective cohort study: treatment, symptoms, and quality of life. Neurosurgery 2012;70:1072-1080.

30. Combs SE, Engelhard C, Kopp C, Wiedenmann N, Schramm O, Prokic V et al. Long-term outcome after highly advanced single-dose or fractionated radiotherapy in patients with vestibular schwannomas - pooled results from 3 large German centers. Radiother Oncol. 2015 Jan:114:378-383.

31. Glasscock ME , Pappas DG Jr, Manolidis S, Von Doersten PG, Jackson CG, Storper IS. Management of acoustic neuroma in the elderly population. Am J Otol.1997 Mar;18(2):236-241. 
Table 1: Patient characteristics and clinical data before treatment

\begin{tabular}{|c|c|c|c|c|c|c|}
\hline \multicolumn{2}{|c|}{ Variable } & $\begin{array}{l}\text { All patients } \\
(n=142)\end{array}$ & $\begin{array}{l}\text { Observation } \\
(n=53)\end{array}$ & $\begin{array}{l}\text { Radiotherapy } \\
(n=46)\end{array}$ & $\begin{array}{l}\text { Microsurgery } \\
(n=43)\end{array}$ & $p$ value \\
\hline \multicolumn{2}{|c|}{ Age (yrs) } & 59.9 & 64.9 & 62.0 & 51.4 & $\begin{array}{l}p<0.0001 \\
(\mathrm{KW})\end{array}$ \\
\hline \multirow[t]{2}{*}{ Sex } & Male & $55(38.7 \%)$ & $20(37.7 \%)$ & $15(32.6 \%)$ & $20(46.5 \%)$ & \\
\hline & Female & $87(61.3 \%)$ & $33(62.3 \%)$ & $31(67.4 \%)$ & $23(53.5 \%)$ & $\begin{array}{l}p=0.3974 \\
(K)\end{array}$ \\
\hline \multicolumn{2}{|c|}{$\begin{array}{l}\text { PTA } \\
\text { thresholds } \\
\text { (dB) }\end{array}$} & $50.83 \pm 29.85$ & $45.05 \pm 23.15$ & $45.79 \pm 24.82$ & $62.75 \pm 37.72$ & $\begin{array}{l}p=0.0932 \\
(\mathrm{KW})\end{array}$ \\
\hline \multicolumn{6}{|c|}{ Gardner } & \multirow{6}{*}{$\begin{array}{l}p=0.0523 \\
\text { (F) }\end{array}$} \\
\hline & I & 37 (26.1\%) & $16(30.2 \%)$ & $11(23.9 \%)$ & $10(23.3 \%)$ & \\
\hline & II & $44(31.0 \%)$ & $16(30.2 \%)$ & $17(37.0 \%)$ & $11(25.6 \%)$ & \\
\hline & III & $41(28.9 \%)$ & $17(32.1 \%)$ & $15(32.6 \%)$ & $9(20.9 \%)$ & \\
\hline & IV & $3(2.1 \%)$ & $1(1.9 \%)$ & $1(2.2 \%)$ & $1(2.3 \%)$ & \\
\hline & V & $17(12.0 \%)$ & $3(5.7 \%)$ & $2(4.3 \%)$ & $12(27.9 \%)$ & \\
\hline \multicolumn{2}{|c|}{$\begin{array}{l}\text { Hearing } \\
\text { deterioration }\end{array}$} & $26.35 \pm 29.58$ & $12.00 \pm 12.25$ & $21.68 \pm 24.42$ & $44.17 \pm 36.23$ & $\begin{array}{l}p<0.0001 \\
(A)\end{array}$ \\
\hline \multicolumn{2}{|c|}{$\begin{array}{l}\text { Hearing } \\
\text { deterioration } \\
\text { per month }\end{array}$} & $2.64 \pm 3.94$ & $0.41 \pm 0.95$ & $2.29 \pm 3.02$ & $5.05 \pm 5.01$ & $\begin{array}{l}p<0.0001 \\
(K W)\end{array}$ \\
\hline \multicolumn{7}{|c|}{$\begin{array}{l}\text { Facial function } \\
(\mathrm{HB})\end{array}$} \\
\hline & 1 & $141(99.3 \%)$ & $53(100 \%)$ & $49(100 \%)$ & $42(97.7 \%)$ & \multirow{6}{*}{$\begin{array}{l}p=0.3028 \\
(F)\end{array}$} \\
\hline & 2 & $0(0.0 \%)$ & $0(0.0 \%)$ & $0(0.0 \%)$ & $0(0.0 \%)$ & \\
\hline & 3 & $0(0.0 \%)$ & $0(0.0 \%)$ & $0(0.0 \%)$ & $0(0.0 \%)$ & \\
\hline & 4 & $1(0.7 \%)$ & $0(0.0 \%)$ & $0(0.0 \%)$ & $1(2.3 \%)$ & \\
\hline & 5 & $0(0.0 \%)$ & $0(0.0 \%)$ & $0(0.0 \%)$ & $0(0.0 \%)$ & \\
\hline & 6 & $0(0.0 \%)$ & $0(0.0 \%)$ & $0(0.0 \%)$ & $0(0.0 \%)$ & \\
\hline \multicolumn{7}{|c|}{ Koos Grade } \\
\hline & 1 & $54(38.0 \%)$ & $44(83.0 \%)$ & $5(10.9 \%)$ & $5(11.6 \%)$ & \multirow{2}{*}{$\begin{array}{l}p<0.0001 \\
(K)\end{array}$} \\
\hline & 2 & $88(62.0 \%)$ & $9(17.0 \%)$ & $41(89.1 \%)$ & $38(88.4 \%)$ & \\
\hline $\begin{array}{l}\text { Tum } \\
(\mathrm{mm}\end{array}$ & r size & $11.7 \pm 4.8$ & $8.4 \pm 4.4$ & $14.5 \pm 3.7$ & $13.1 \pm 3.6$ & $\begin{array}{l}p<0.0001 \\
(K W)\end{array}$ \\
\hline \multicolumn{7}{|c|}{ Tinnitus } \\
\hline & yes & $69(48.6 \%)$ & $34(64.2 \%)$ & $18(39.1 \%)$ & 17 (39.5\%) & \multirow{2}{*}{$\begin{array}{l}p=0.0166 \\
(K)\end{array}$} \\
\hline & no & $73(51.4 \%)$ & $19(35.8 \%)$ & $28(60.9 \%)$ & $26(60.5 \%)$ & \\
\hline \multicolumn{7}{|c|}{ Vertigo } \\
\hline & yes & $68(47.9 \%)$ & $28(52.8 \%)$ & $19(41.3 \%)$ & $21(48.8 \%)$ & \multirow{2}{*}{$\begin{array}{l}p=0.5134 \\
(K)\end{array}$} \\
\hline & no & $74(52.1 \%)$ & $25(47.2 \%)$ & $27(58.7 \%)$ & $22(51.2 \%)$ & \\
\hline
\end{tabular}

Qualitative parameters: effective (\%), $\times 2$ test(K) and Fisher (F).

Quantitative parameters: mean \pm standard deviation, Kruskal-Wallis tests(KW).

PTA auditory thresholds: calculated on mean of thresholds for frequencies 500, 1000, 2000 and $3000 \mathrm{~Hz}(\mathrm{~dB}$ $\mathrm{HL})$

HB: House and Brackmann facial nerve grading scale

Hearing deterioration: Hearing threshold deterioration in $\mathrm{dB}$ between initial diagnosis and just before treatment for radiotherapy and microsurgery, and between diagnosis and last news for the observation group, calculated on mean of thresholds for frequencies $500,1000,2000$ and $3000 \mathrm{~Hz}(\mathrm{~dB} \mathrm{HL})$

Hearing deterioration per month: Hearing threshold deterioration per month in $\mathrm{dB}$ between initial diagnosis and just before treatment for radiotherapy and microsurgery, and between diagnosis and last news for the observation group, calculated on mean of thresholds for frequencies 500, 1000, 2000 and $3000 \mathrm{~Hz}(\mathrm{~dB} \mathrm{HL})$ 
Table 2: Clinical outcomes after treatment

\begin{tabular}{|c|c|c|c|c|c|}
\hline Variable & $\begin{array}{l}\text { All patients } \\
(n=142)\end{array}$ & $\begin{array}{l}\text { Observation } \\
(n=53)\end{array}$ & $\begin{array}{l}\text { Radiotherapy } \\
(n=46)\end{array}$ & $\begin{array}{l}\text { Microsurgery } \\
(n=43)\end{array}$ & $p$ \\
\hline $\begin{array}{l}\text { Mean follow-up } \\
\text { (months) }\end{array}$ & $65.6 \pm 31.3$ & $60.9 \pm 19.9$ & $56.8 \pm 32.7$ & $80.7 \pm 36.1$ & $\begin{array}{l}p=0.0065 \\
(\mathrm{KW})\end{array}$ \\
\hline $\begin{array}{l}\text { PTA } \\
\text { thresholds } \\
\text { (dB) }\end{array}$ & $\begin{array}{l}75.38 \pm \\
36.32\end{array}$ & $54.20 \pm 26.85$ & $70.09 \pm 31.94$ & $106.92 \pm 28.55$ & $\begin{array}{l}p<0.0001 \\
(K W)\end{array}$ \\
\hline \multicolumn{6}{|l|}{ Gardner } \\
\hline 1 & $15(10.6 \%)$ & $10(18.9 \%)$ & $4(8.7 \%)$ & $1(2.3 \%)$ & \multirow{5}{*}{$\begin{array}{l}p<0.0001 \\
(F)\end{array}$} \\
\hline ॥ & $28(19.7 \%)$ & $18(34.0 \%)$ & $7(15.2 \%)$ & $3(7.0 \%)$ & \\
\hline III & $45(31.7 \%)$ & $17(32.1 \%)$ & $24(52.2 \%)$ & $4(9.3 \%)$ & \\
\hline IV & $6(4.2 \%)$ & $5(9.4 \%)$ & $1(2.2 \%)$ & $0(0.0 \%)$ & \\
\hline V & $48(33.8 \%)$ & $3(5.7 \%)$ & $10(21.7 \%)$ & $35(81.4 \%)$ & \\
\hline \multicolumn{6}{|l|}{$\begin{array}{l}\text { Facial function } \\
(\mathrm{HB})\end{array}$} \\
\hline 1 & $126(88.7 \%)$ & $53(100 \%)$ & $46(100 \%)$ & $27(62.8 \%)$ & \multirow{6}{*}{$\begin{array}{l}p<0.0001 \\
(F)\end{array}$} \\
\hline 2 & $10(7.0 \%)$ & $0(0.0 \%)$ & $0(0.0 \%)$ & $10(23.3 \%)$ & \\
\hline 3 & $4(2.8 \%)$ & $0(0.0 \%)$ & $0(0.0 \%)$ & $4(9.3 \%)$ & \\
\hline 4 & $1(0.7 \%)$ & $0(0.0 \%)$ & $0(0.0 \%)$ & $1(2.3 \%)$ & \\
\hline 5 & $1(0.7 \%)$ & $0(0.0 \%)$ & $0(0.0 \%)$ & $1(2.3 \%)$ & \\
\hline 6 & $0(0.0 \%)$ & $0(0.0 \%)$ & $0(0.0 \%)$ & $0(0.0 \%)$ & \\
\hline \multicolumn{6}{|l|}{ Tinnitus } \\
\hline yes & $82(57.7 \%)$ & $34(64.2 \%)$ & $22(47.8 \%)$ & $26(60.5 \%)$ & \multirow{2}{*}{$\begin{array}{l}p=0.2373 \\
(K)\end{array}$} \\
\hline no & $60(42.3 \%)$ & $19(35.8 \%)$ & $24(52.2 \%)$ & $17(39.5 \%)$ & \\
\hline \multicolumn{6}{|l|}{ Vertigo } \\
\hline yes & $69(48.6 \%)$ & $28(52.8 \%)$ & $23(50.0 \%)$ & $18(41.9 \%)$ & \multirow{2}{*}{$\begin{array}{l}p=0.5495 \\
(K)\end{array}$} \\
\hline no & $73(51.4 \%)$ & $25(47.2 \%)$ & $23(50.0 \%)$ & $25(58.1 \%)$ & \\
\hline
\end{tabular}

Qualitative parameters: effective (\%), $\times 2$ test $(\mathrm{K})$ and Fisher $(\mathrm{F})$.

Quantitative parameters: mean \pm standard deviation, Kruskal-Wallis tests(KW)

PTA auditory thresholds: calculated on mean of thresholds for frequencies 500, 1000, 2000 and $3000 \mathrm{~Hz}$ (dB

$\mathrm{HL})$

HB: House-Brackmann facial nerve grading scale 
Table 3: Clinical outcomes after treatment in microsurgery group

\begin{tabular}{|c|c|c|c|}
\hline Variable & $\begin{array}{l}\text { Middle fossa approach } \\
(n=15)\end{array}$ & $\begin{array}{l}\text { Translabyrinthine } \\
\text { approach } \\
(n=28)\end{array}$ & $\mathbf{p}$ \\
\hline Mean follow-up (months) & $82 ; 40 \pm 36.53$ & $79.71 \pm 36.55$ & $p=0.6425(W)$ \\
\hline Koos grade & & & $p=0.6427(F)$ \\
\hline 1 & $1(6.7 \%)$ & $4(14.3 \%)$ & \\
\hline 2 & $14(93.3 \%)$ & $24(85.7 \%)$ & \\
\hline Tumor size (mm) & $13.30 \pm 3.32$ & $12.96 \pm 3.87$ & $p=0.7891(S)$ \\
\hline $\begin{array}{l}\text { PTA thresholds } \\
\text { (dB) } \\
\text { Gardner }\end{array}$ & $84.08 \pm 38.13$ & $120 \pm 0$ & $\begin{array}{l}p=0.0003(W) \\
p=0.0002(F)\end{array}$ \\
\hline I & $1(6.3 \%)$ & $0(0 \%)$ & \\
\hline$\|$ & $2(13.3 \%)$ & $0(0 \%)$ & \\
\hline III & $4(26.7 \%)$ & $0(0 \%)$ & \\
\hline IV & $0(0 \%)$ & $0(0 \%)$ & \\
\hline V & $8(53.3 \%)$ & $28(100 \%)$ & \\
\hline Facial function (HB) & & & $p=0.0076(F)$ \\
\hline 1 & $5(33.3 \%)$ & $22(78.6 \%)$ & \\
\hline 2 & $7(46.7 \%)$ & $3(10.7 \%)$ & \\
\hline 3 & $2(13.3 \%)$ & $2(7.1 \%)$ & \\
\hline 4 & $1(6.7 \%)$ & $0(0 \%)$ & \\
\hline 5 & $0(0 \%)$ & $1(3.6 \%)$ & \\
\hline 6 & $0(0 \%)$ & $0(0 \%)$ & \\
\hline Tinnitus & & & $p=0.9636(K)$ \\
\hline yes & $9(60.0 \%)$ & $17(60.7 \%)$ & \\
\hline no & $6(40.0 \%)$ & $11(39.3 \%)$ & \\
\hline Vertigo & & & $p=0.4068(K)$ \\
\hline yes & $5(33.3 \%)$ & $13(46.4 \%)$ & \\
\hline no & $10(66.7 \%)$ & $15(53.6 \%)$ & \\
\hline
\end{tabular}

Qualitative parameters: effective (\%), X2 test(K) and Fisher (F).

Quantitative parameters: mean \pm standard deviation, Kruskal-Wallis tests $(\mathrm{KW})$.

PTA auditory thresholds: calculated on mean of thresholds for frequencies 500, 1000, 2000 and $3000 \mathrm{~Hz}(\mathrm{~dB}$ $\mathrm{HL})$

HB: House-Brackmann facial nerve grading scale 
Table 4: SF-36 results in each group

\begin{tabular}{llllll}
\hline Variable & $\begin{array}{l}\text { All patients } \\
(\mathbf{n = 1 4 2})\end{array}$ & $\begin{array}{l}\text { Observation } \\
(\mathbf{n = 5 3})\end{array}$ & $\begin{array}{l}\text { Radiotherapy } \\
(\mathbf{n = 4 6 )}\end{array}$ & $\begin{array}{l}\text { Microsurgery } \\
(\mathbf{n = 4 3 )}\end{array}$ & $\boldsymbol{p}$ \\
\hline Physical functioning & $80.80 \pm 22.91$ & $79.93 \pm 24.41$ & $80.89 \pm 22.03$ & $81.78 \pm 22.41$ & $p=0.8069$ \\
Role-physical & $57.67 \pm 39.78$ & $64.54 \pm 39.40$ & $56.11 \pm 40.30$ & $51.16 \pm 39.32$ & $p=0.2632$ \\
Body pain & $74.42 \pm 29.52$ & $74.77 \pm 30.31$ & $74.27 \pm 30.28$ & $74.14 \pm 28.39$ & $p=0.9813$ \\
Mental health & $68.10 \pm 20.13$ & $68.04 \pm 19.68$ & $68.62 \pm 21.86$ & $67.61 \pm 19.20$ & $p=0.8781$ \\
Role-emotional & $72.99 \pm 39.09$ & $77.12 \pm 36.20$ & $71.97 \pm 41.88$ & $69.05 \pm 39.91$ & $p=0.5868$ \\
Social functioning & $77.48 \pm 25.28$ & $81.13 \pm 20.16$ & $75.82 \pm 28.19$ & $74.70 \pm 27.68$ & $p=0.7528$ \\
Vitality & $55.17 \pm 22.11$ & $53.62 \pm 21.70$ & $57.72 \pm 22.03$ & $54.31 \pm 23.00$ & $p=0.5991$ \\
General health & $58.74 \pm 20.30$ & $58.66 \pm 20.11$ & $56.20 \pm 20.59$ & $61.73 \pm 20.34$ & $p=0.6055$ \\
$\begin{array}{l}\text { Physical component } \\
\text { summary }\end{array}$ & $46.46 \pm 10.18$ & $46.83 \pm 11.34$ & $46.17 \pm 9.31$ & $46.30 \pm 9.76$ & $p=0.6726$ \\
$\begin{array}{l}\text { Mental component } \\
\text { summary }\end{array}$ & $46.97 \pm 11.30$ & $47.61 \pm 10.88$ & $47.15 \pm 12.56$ & $45.97 \pm 10.61$ & $p=0.5923$ \\
\hline
\end{tabular}

SF36: Health Survey Short-Form

Quantitative parameters: mean \pm standard deviation, Kruskal-Wallis test. 
Table 5: Physical and mental component summary of Health Survey Short-Form 36 in patients suffering or not from vertigo and tinnitus in each group

\begin{tabular}{|c|c|c|c|c|c|}
\hline & & Physical score & $\mathbf{p}$ & Mental score & $\mathbf{p}$ \\
\hline \multicolumn{6}{|c|}{ All patients } \\
\hline Vertigo & $\begin{array}{l}\text { yes } \\
\text { no }\end{array}$ & $\begin{array}{l}43.3 \pm 10.0 \\
49.4 \pm 9.5\end{array}$ & $p<0.0001$ & $\begin{array}{l}41.3 \pm 11.5 \\
52.3 \pm 8.1\end{array}$ & $p<0.0001$ \\
\hline Tinnitus & $\begin{array}{l}\text { yes } \\
\text { no }\end{array}$ & $\begin{array}{l}45.5 \pm 10.4 \\
47.7 \pm 9.8\end{array}$ & $p=0.1634$ & $\begin{array}{l}44.8 \pm 11.8 \\
49.7 \pm 10.2\end{array}$ & $p=0.0137$ \\
\hline \multicolumn{6}{|c|}{ Observation } \\
\hline Vertigo & $\begin{array}{l}\text { yes } \\
\text { no }\end{array}$ & $\begin{array}{l}44.5 \pm 10.1 \\
49.3 \pm 12.2\end{array}$ & $p=0.0113$ & $\begin{array}{l}42.6 \pm 10.5 \\
52.8 \pm 8.8\end{array}$ & $p=0.0003$ \\
\hline Tinnitus & $\begin{array}{l}\text { yes } \\
\text { no }\end{array}$ & $\begin{array}{l}46.7 \pm 11.8 \\
47.0 \pm 10.8\end{array}$ & $p=0.9612$ & $\begin{array}{l}46.3 \pm 12.2 \\
49.8 \pm 7.9\end{array}$ & $p=0.3967$ \\
\hline \multicolumn{6}{|c|}{ Radiotherapy } \\
\hline Vertigo & $\begin{array}{c}\text { yes } \\
\text { no }\end{array}$ & $\begin{array}{l}44.6 \pm 10.0 \\
47.7 \pm 8.6\end{array}$ & $p=0.2198$ & $\begin{array}{l}40.9 \pm 13.7 \\
53.1 \pm 7.9\end{array}$ & $p=0.0023$ \\
\hline Tinnitus & $\begin{array}{l}\text { yes } \\
\text { no }\end{array}$ & $\begin{array}{l}46.4 \pm 8.5 \\
46.0 \pm 10.1\end{array}$ & $p=0.8353$ & $\begin{array}{l}44.5 \pm 13.3 \\
49.2 \pm 11.8\end{array}$ & $p=0.2454$ \\
\hline \multicolumn{6}{|c|}{ Microsurgery } \\
\hline Vertigo & $\begin{array}{l}\text { yes } \\
\text { no }\end{array}$ & $\begin{array}{l}40.2 \pm 9.7 \\
51.3 \pm 6.6\end{array}$ & $p=0.0008$ & $\begin{array}{l}39.7 \pm 10.6 \\
51.1 \pm 7.6\end{array}$ & $p=0.0012$ \\
\hline \multirow[t]{2}{*}{ Tinnitus } & yes & $43.2 \pm 9.9$ & & $43.2 \pm 11.4$ & \\
\hline & no & $50.9 \pm 7.7$ & $p=0.0157$ & $47.5 \pm 10.0$ & $p=0.0484$ \\
\hline
\end{tabular}

Quantitative parameters: mean \pm standard deviation, Mann-Whitney Wilcoxon test. 
Table 6: $\mathrm{HHI}$ results

\begin{tabular}{|c|c|c|c|c|c|}
\hline Variable & $\begin{array}{l}\text { All patients } \\
(n=142)\end{array}$ & $\begin{array}{l}\text { Observation } \\
(n=53)\end{array}$ & $\begin{array}{l}\text { Radiotherapy } \\
(n=46)\end{array}$ & $\begin{array}{l}\text { Microsurgery } \\
(n=43)\end{array}$ & $p$ \\
\hline Total HHI & $19.62 \pm 11.66$ & $17.74 \pm 11.35$ & $20.22 \pm 12.05$ & $21.30 \pm 11.56$ & $\begin{array}{l}p=0.3054 \\
(K W)\end{array}$ \\
\hline Emotional $\mathrm{HHI}$ & $8.94 \pm 6.39$ & $7.81 \pm 6.04$ & $9.39 \pm 6.43$ & $9.86 \pm 6.70$ & $\begin{array}{l}p=0.3252 \\
(\mathrm{KW})\end{array}$ \\
\hline Social HHI & $10.68 \pm 5.73$ & $9.92 \pm 5.66$ & $10.83 \pm 6.07$ & $11.44 \pm 5.44$ & $\begin{array}{l}p=0.4125 \\
(K W)\end{array}$ \\
\hline \multicolumn{6}{|l|}{$\begin{array}{l}\text { HHI auditory } \\
\text { disorders }\end{array}$} \\
\hline yes & $109(76.8 \%)$ & $39(73.6 \%)$ & $36(78.3 \%)$ & $34(79.1 \%)$ & \multirow[b]{2}{*}{$p=0.7950(F)$} \\
\hline no & $33(23.2 \%)$ & $14(26.4 \%)$ & $10(21.7 \%)$ & $9(20.9 \%)$ & \\
\hline
\end{tabular}

$\mathrm{HHI}$ : Hearing Handicap Inventory

Quantitative parameters: mean \pm standard deviation, Kruskal-Wallis test $(\mathrm{KW})$

Qualitative parameters: number of subjects (\%), Fisher test( $F)$. 
Table 7: THI results

\begin{tabular}{lccccc}
\hline Variable & $\begin{array}{c}\text { All patients } \\
(\mathbf{n = 1 4 2})\end{array}$ & $\begin{array}{c}\text { Observation } \\
(\mathbf{n = 5 3})\end{array}$ & $\begin{array}{c}\text { Radiotherapy } \\
(\mathbf{n = 4 6})\end{array}$ & $\begin{array}{c}\text { Microsurgery } \\
(\mathbf{n = 4 3 )}\end{array}$ & $p$ \\
\hline Total THI & $19.48 \pm 25.19$ & $21.17 \pm 24.21$ & $15.83 \pm 21.80$ & $21.30 \pm 29.57$ & $p=0.4160(\mathrm{KW})$ \\
Functional THI & $9.19 \pm 12.37$ & $9.75 \pm 11.86$ & $7.52 \pm 10.27$ & $10.28 \pm 14.90$ & $p=0.5164(\mathrm{KW})$ \\
Emotional THI & $5.80 \pm 8.24$ & $6.47 \pm 7.84$ & $4.78 \pm 7.61$ & $6.05 \pm 9.38$ & $p=0.2659(\mathrm{KW})$ \\
Catastrophic THI & $4.51 \pm 5.62$ & $4.92 \pm 5.64$ & $3.52 \pm 5.05$ & $5.07 \pm 6.15$ & $p=0.3924(\mathrm{KW})$ \\
Intensity & & & & & \\
$\quad$ Low & $82(57.7 \%)$ & $25(47.2 \%)$ & $29(63.0 \%)$ & $28(65.1 \%)$ & \\
$\quad$ Moderate & $32(22.5 \%)$ & $17(32.1 \%)$ & $10(21.7 \%)$ & $5(11.6 \%)$ & \\
$\quad$ Medium & $11(7.7 \%)$ & $5(9.4 \%)$ & $4(8.7 \%)$ & $2(4.7 \%)$ & $p=0.2509(\mathrm{~F})$ \\
$\quad$ Severe & $12(8.5 \%)$ & $4(7.5 \%)$ & $2(4.3 \%)$ & $6(14.0 \%)$ & \\
$\quad$ Catastrophic & $5(3.5 \%)$ & $2(3.8 \%)$ & $1(2.2 \%)$ & $2(4.7 \%)$ & \\
\hline THI Tinnitus Handicap Inventory & & & &
\end{tabular}

THI : Tinnitus Handicap Inventory

Quantitative parameters: mean \pm standard deviation, Kruskal-Wallis test (KW)

Qualitative parameters: number of subjects (\%), Fisher test (F) 
Table 8: DHI Short-Form results

\begin{tabular}{llllll}
\hline Variable & $\begin{array}{c}\text { All patients } \\
(\mathbf{n = 1 4 2})\end{array}$ & $\begin{array}{c}\text { Observation } \\
(\mathbf{n = 5 3})\end{array}$ & $\begin{array}{c}\text { Radiotherapy } \\
(\mathbf{n = 4 6})\end{array}$ & $\begin{array}{c}\text { Microsurgery } \\
(\mathbf{n = 4 3})\end{array}$ & $\mathbf{p}$ \\
\hline Global DHI & $9.67 \pm 3.44$ & $9.67 \pm 3.38$ & $9.83 \pm 3.57$ & $9.51 \pm 3.46$ & $p=0.7573$ \\
Emotional DHI & $1.80 \pm 0.55$ & $1.81 \pm 0.60$ & $1.78 \pm 0.55$ & $1.81 \pm 0.50$ & $p=0.9168$ \\
Functional DHI & $4.44 \pm 1.74$ & $4.44 \pm 1.72$ & $4.54 \pm 1.75$ & $4.33 \pm 1.80$ & $p=0.7104$ \\
Physical DHI & $3.43 \pm 1.69$ & $3.42 \pm 1.66$ & $3.50 \pm 1.79$ & $3.37 \pm 1.66$ & $p=0.8216$ \\
\hline
\end{tabular}

DHI: Dizziness handicap inventory

Quantitative parameters: mean \pm standard deviation, Kruskal-Wallis test $(\mathrm{KW})$ 